\title{
1 The potential impacts of the songbird trade on mixed-species flocking
}

3 Abstract Mixed-species flocking is an important avian social system that supports a large number of species. Current reviews of threats to mixed flocks have only examined two types of anthropogenic pressures: different land use intensity and fragmentation. We highlight the bird trade as another major potential threat for many mixed-species flocking species in Southeast Asia. We examine the potential indirect impact of the bird trade by comparing social networks of flocking data collected over two periods nearly 20 years apart (1997 and 2016) from the same site in Sumatra, Indonesia. We find that the structure of the two networks were significantly correlated. However, of the 90 species observed, 49 had previously been identified as part of the bird trade. These species experienced a significantly greater decrease in network centrality over time compared to the non-traded species, resulting in a loss of structure in the mixed-species flocking network. Simulating further disturbances suggests that flocks may not be resilient to the complete loss of two or more traded species. Our results suggest that the widespread declines in those other species that also rely on mixed-species flocking.

Key words: mixed-species flocks, community ecology, illegal wildlife trade, IUCN, resilience, 
21 There is increasing awareness of the need to conserve ecological networks. Interactions

22 between species, such as pollinator-plant networks (Burkle, Marlin, \& Knight, 2013) and

23 predator-prey food webs (Dunne, Williams, \& Martinez, 2002), are widespread and form an

24 essential part of ecosystem functioning. One very common, but often overlooked system of

25 interactions are mixed-species groups. For example, mixed-species bird flocks ('mixed flocks'

26 hereafter) have been reported in many parts of the world (Munn 1985; Hutto 1994; Develey \&

27 Peres 2000; Lee et al. 2005; Sridhar \& Shanker 2014). They can represent a significant proportion of the avifauna (e.g. over 50\% of species reported in Madagascar, Eguchi et al. 1993;

29 in Australia, Bell 1983; and in the Dominican Republic, Latta \& Wunderle 1996) and many

30 species are obligate flock members. In mixed flocks, participants (two or more species) travel

31 together in search of dispersed food (Buskirk 1976; Bell 1983), actively maintaining group

32 cohesion with both conspecifics and heterospecifics (Farine et al. 2014). Doing so can bring

33 important fitness benefits for participants (Dolby \& Grubb 1998), and the survival rates of obligate mixed flock members has been shown to be significantly higher than for species feeding alone or in pairs (Jullien \& Clobert 2000). Thus, conserving mixed-species flocks is likely

36 to be important for maintaining the presence and abundance of many species.

Mixed flock formation can be highly sensitive to environmental change (Mokross et al. 2014),

39 and, in particular, the loss of key species can fundamentally alter the dynamics of mixed flock

40 composition (e.g., Maldonado-Coelho \& Marini 2000). This could be because flocking can

41 facilitate transfer of information about food resources among individuals (Aplin et al. 2012), 
42 with some species playing a keystone role in spreading information about new food resources

43 (Suzuki 2012; Farine et al. 2015). Flocking can also confer anti-predator benefits (e.g., Thiollay

44 1999), with certain species providing significant vigilance benefits (Goodale \& Kotagama 2005,

45 Martinez \& Zenil 2002, Martinez et al. 2016). Species in mixed flocks are typically thought to

46 take on one of two different roles: nuclear species (the initiator of mixed flocks) and attendant

47 species (Moynihan 1962); and nuclear species have been shown to provide important benefits

48 for attendant species that cannot be gained in their absence (Dolby \& Grubb 1998). However, in

49 terms of ecosystem function, the loss of a common attendant species could be equally severe if

50 these bring survival benefits to nuclear species via group augmentation or by providing foraging

51 benefits (e.g. Satischandra et al. 2007). Thus, identifying species that are central in their

52 communities, both nuclear or attendant, and identifying key threats they face is an important

53 goal for conservation biologists (Goodale, Beauchamp, \& Ruxton, 2017).

54

55 Human disturbances are a major source of threats for ecosystems worldwide. Two main

56 anthropogenic disturbance impacts to mixed flocks have been studied: forest fragmentation

57 and different land-use intensity (see review by Goodale et al. 2015). Across studies, evidence

58 suggests that disturbed areas typically contain smaller flocks with reduced species richness

59 (Goodale et al. 2015). A few recent studies have also suggested that community structure (i.e.

60 the network of interactions among species) can also be affected (Mokross et al. 2014), with the

61 changing composition of species in the landscape impacting how species interact with one-

62 another (Mammides et al. 2015). This community-centric approach is important because it

63 more directly links anthropogenic disturbances to functional change in the communities 
64 involved. Such an approach is likely to be particularly important for disturbances in which the

65 impacts may be as severe as those caused by habitat disturbances, but where the cues much

66 less noticeable. One such potential threat, that has yet to be examined in the context of

67 conservation of avian communities, is bird trapping.

68

69 The wild bird trade is widespread in South-east Asia. Thousands of birds are sold to fulfill

70 various purposes: as pets or household ornaments, for food, religious release, traditional

71 medicine (Jepson \& Ladle 2009; Shepherd 2012), or for bird singing competitions (where bird

72 owners use species such as White-rumped Shama Kittacincla malabarica and compete for the

73 best song; Eaton et al. 2015). Birds are sourced both locally and more widely. A recent

74 assessment in the three largest bird markets in Jakarta shows that $98 \%$ of the total volume of

75 birds traded (182 species) are native to Indonesia (Chng et al. 2015). However, the enormous

76 demand for birds (the wildlife trade is worth an estimated US\$2.5 billion/year in East Asia and

77 the Pacific, and perhaps up to USD\$1 billion/year in Indonesia alone; UNODC 2013) has severely

78 depleted animal populations in local forests. For example, many of the wild bird species that

79 are sold in the markets of Jakarta (on Java) are becoming very rare and now being sourced from

80 neighbouring Sumatra (Jepson \& Laddle 2009, Shepherd 2012, Chng et al. 2016). If the same

81 species that are being trapped and traded are also species that are central in mixed flocks, for

82 example drongos are among the most commonly traded species (Shepherd 2012, Chng et al.

83 2016) and often considered as being nuclear in mixed flocks (Satischandra et al. 2007), then the

84 loss of these species could alter the entire structure of communities. Subsequently, this could 
85 have significant repercussions on the behaviour of remaining species in the community (Dolby

\& Grubb 1999), with potential carry-over effects into foraging and reproductive success.

87

In this study, we investigate the potential indirect effects of bird trapping to have an impact on the formation and maintenance of mixed-species flocks. We conducted two surveys (1997 and 2016) in Lampung Province, in southwest Sumatra, Indonesia, where birds are actively being targeted for the bird trade (see Fig. 1 for example). We use social network analysis to investigate changes in the community structure over time. Social network analysis provides a powerful toolbox for quantifying structural properties of multi-species communities, thus moving beyond simple descriptors of flocking propensity. Specifically, it provides quantitative measures of the importance of each species (i.e. its centrality, determined by the extent of cooccurrences in flocks with other species) as well as modelling tools (i.e. null models similar to important for the ongoing functioning of the system.

101

102 The aim of our study is to assess the changes in flocking structure in a protected area that has experienced ongoing illegal bird trapping. Specifically, we use mixed flock networks generated

104 from our two surveys to test (i) whether networks in the two years are more structured than 105 expected under indiscriminate flocking (showing preferred associations between certain 106 species), (ii) whether the propensities for species to flock together (and thus the resulting 
107 network structure) are correlated over the two survey periods spanning 19 years, (iii) whether

108 traded species and non-traded species differ in their social network centrality, (iv) whether the 109 centrality of traded and non-traded species changed over time, and ( $v$ ) whether the mixed flock

110 networks are resilient to the complete removal of traded species. Our study also represents the 111 first major dataset on mixed flocks from Sumatra.

\section{Study area}

114 The Way Canguk Research Station (Lat. -5.658643, Long. 104.407098; Fig. 2) is located inside 115 the Bukit Barisan Selatan National Park (325,000 ha) and was established in 1997. The national 116 park is the third largest protected area in Sumatra, and contains some of the last intact areas of 117 lowland rainforest on this island (O’Brien \& Kinnaird 1996). Our study was conducted along a 118 trail system covering an area of approximately 380-ha of intact lowland forest contained within 119 the Way Canguk Research Station area. The study area, and the research station, are 120 surrounded by a larger contiguous primary forest (the national park), while the national park is 121 surrounded by matrix of intact forest, burned forest, areas disturbed by illegal logging, and 122 agricultural lands. Illegal logging and encroachment for agricultural expansion are the main

123 threats to the national park, but this is not a threat inside the research station itself (Gaveau et 124 al. 2007). Two main anthropogenic disturbances occur in the Way Canguk Research Station: 125 forest fires and bird trapping. Forest fires occurred twice: 165 ha were burned in 1997/1998 126 (Kinnaird \& O’Brien 1998) and in 2015, 7 ha of this previously damaged forest was burned a 127 second time (William Marthy pers. obs.). However, we conducted all surveys in areas more than $128600 \mathrm{~m}$ (beyond the impact of fire in this community, Adeney et al. 2006) and buffered by a river 
129 from areas affected by fire, and thus do not believe it has a confounding effect. By contrast, 130 trapping of birds for trade has persisted on Way Canguk Research Station, and in our specific 131 study area, since the late 1990's (O'Brien \& Kinnaird 1996, Harris et al. 2017), and continues to 132 occur despite the presence of the research station staff and increased patrolling efforts in the 133 larger Bukit Barisan Selatan National Park (unpublished data based on interviews of research 134 station and national parks staff). For example, between 2014 and early 2017, the research 135 station staff recorded 13 incidents of bird trapping: in 10 instances the staff found evidence 136 that bird trapping had occurred (i.e. dead birds, camps, poles for nets), and in three instances

137 the staff met directly with the perpetrators (in two instances the perpetrators were arrested). 138 As a consequence of trapping, two of targeted species, the White-rumped shama and the Grey139 cheeked bulbul Alophoixus bres are now extremely rare, although a recent study by Harris et al. 140 (2017) suggests that abundances of birds in the study area have remained relatively stable.

141 Trappers active in the research station area typically use a lure (e.g. a male Blue-winged

142 Leafbird Chloropsis moluccensis; Fig. 1) to attract and capture target birds in mist-nets or with 143 bird-lime (an adhesive made from tree sap; Sheppard et al. 2004). During the capture process, 144 other species can also be caught (i.e. as 'bycatch'). Individuals of these species can be released, 145 die or be killed (e.g. Fig. 1), or kept by trappers.

\section{Data collection}

149 Field observations 
150 We conducted two surveys, the first between July and October 1997 for a total of 24

151 observation days, and the second between August and November 2016 for a total of 18

152 observation days. Observations were made by the same observer (WM) and along the same

153 trail system, which had been cut and mapped through the forest in order to facilitate

154 observation of the avifauna. Both surveys were done during the non-breeding season for most

155 species (van Marle \& Voous 1988), and the habitat (primary forest) remained the same across

156 both surveys.

157

158 Mixed flocks were broadly defined as two or more bird species moving together in the same 159 general direction (Buskirk 1976; Hutto 1994), and within the relative vicinity of each other 160 approximately 10-25 metres of each other (Bell 1983; Hutto 1987). Each day, we walked

161 through the study area from 07.00 to $17.00 \mathrm{~h}$ to search for flocks. For each flock we collected:

162 time, location of flock in the study area, participating species, and the number of individuals.

163 Flocks were followed for as long as possible (maximum one hour) to record all species present.

164 During observations, the observer briefly recounted species every 10 minutes to check for 165 species that had been missed. Upon leaving a flock, the observer moved several hundred 166 meters in a different direction to the flock trajectory before counting any new flocks, and aimed 167 to cover a large area each day to avoid re-encountering the same flock twice. Both surveys used 168 identical methodology. Our approaches are consistent with previous studies, e.g. mixed flocks 169 observed in similar locations but on different days are considered as different (e.g. Sridhar et al. 170 2013). We did not apply filtering techniques to remove species with few observations as we 171 used weighted network metrics (see below). 


\section{Trade status}

174 Because raw data on the trapping effort for the bird trade are not available, we sourced data

175 from market surveys to identify which species in our dataset are regularly traded. We used

176 literature from markets in both Sumatra and Jakarta as many of the wild birds sold in the Javan

177 markets are now sourced from Sumatra (Jepson \& Laddle 2009; Shepherd 2012; Chng et al.

178 2016) and there is clear evidence that the bird trade is a large market spanning the entire

179 region (with birds being illegally shipped to neighbouring countries,

180 http://www.traffic.org/home). As raw data on trapping takes were not available, we created a

181 scoring system to estimate the likelihood for each species to be regularly traded. Species that

182 have been directly identified as being harvested from the forests of Sumatra (using Shepherd et

183 al. 2004; Shepherd 2006; Harris et al. 2017) were given a score of 1. Because species traded in

184 Java are now frequently sourced from Sumatra (Jepson \& Laddle 2009, Shepherd 2012, Chng et

185 al. 2016), including from Bukit Barisan Selatan National Park, we added 0.5 to the score for

186 species identified in bird markets in Java (using data from Jepson \& Ladle 2009; Chng et al.

187 2015). For species recorded in bird markets in multiple published surveys (our cited sources

188 span approximately 10 years), we added 1 to the score (continuous impact). Hence, the highest

189 score for a species was 2.5. While we were unable to account for intensity at which each

190 species is traded, our system aims to increase the weighting of species that have been

191 repeatedly reported in markets, known to be traded locally (observed in markets in Sumatra),

192 and found to be traded in several regions (suggesting that they are commonly traded). We

193 developed the scoring system based on our own observations (e.g. we have independently 
noted that species are traded across Indonesian islands), and validated the scores in consultation with park rangers and local conservation staff. For example, species with the highest trade scores are commonly known to be traded (e.g. Greater racket-tailed drongo

197 Dicrurus paradiseus and Blue-winged leafbird, which were noted as among the most common

198 in Sumatran markets by Shepherd 2006 during our study period, both scored 2.5 using our

199 framework), although we do not strictly interpret the trade scores in this way. However,

200 because of potential limitations of our trade score in evaluating the trade pressure on a given

201 species, we also discuss our results in terms of traded versus non-traded (i.e. binary) status and

202 perform several analyses that support our findings independently of using the trade score

203 (based mostly on Harris et al. 2017, a study conducted at the same study site).

204

205 Data analysis

206 For each sampling period (1997 and 2016), we generated an undirected social network for each

207 observation period. Each node in this network represents a species. The edges between nodes

208 represent the probability that the two species are observed in the same mixed flock given that

209 at least one was observed in the flock. We used the "gambit of the group" approach, meaning

210 that all species within a particular mixed flock are considered to be connected (Whitehead \&

211 Dufault 1999, Franks et al. 2010, Mokross et al. 2014). We then used the "get_network"

212 function in the asnipe R package (Farine 2013) to calculate the edge weights and create the

213 network. The sum of the edge weights connected to a given node (species) is called its

214 weighted degree. This measure of centrality that represents that node's structural importance 
215 in the community (Farine \& Whitehead 2015). All computations were conducted in R version

216 3.1.2. (R Core Team 2014).

Are networks more structured than expected under indiscriminate flocking?

To determine if mixed flocks represent non-random co-occurrences, we compared each network to an expectation by chance constructed using a permutation test (see Farine 2017). In this analysis, we created a null model using a pre-network randomisation where we swapped

222 the observation of species among groups (Farine \& Whitehead 2015). That is, for each step in 223 the permutation process, we selected two species from two flocks in which the species did not 224 co-occur, swapped them (following the algorithm first described by Bejder et al. 1998), and 225 recalculated the network (herein called a randomised network). We then compared the 226 Coefficient of Variation (CV: the standard deviation of the edge weights divided by the mean of 227 the edge weights) of the observed network (CVobserved) to the CV of 1500 randomized 228 networks (CVrandom). A CVobserved larger than 95\% of the values of CVrandom suggests that 229 the observed network contains more preferred/avoided relationships than expected under a 230 scenario in which species form the same size flocks, but associate with other species at random 231 (Farine \& Whitehead 2015). P values were calculated by taking the number of times the value 232 from the random networks were larger than the values from the observed network, divided by 233 the number of permutations (Farine 2017). Our permutation test is an important part of our 234 analyses as it controls for the observed abundance of each species in each sample by keeping 235 the total number of observations per species constant in both the observed and the 236 randomized networks. Thus, any differences arising are only due to the patterns in mixed flock 
237 composition and not potential changes in abundance of each species participating in mixed 238 flocks over the two time periods.

240 Are the 1997 and 2016 networks correlated?

241 To establish whether there was some baseline similarities across our two sampling periods, we

242 used a Mantel test to determine whether the edge weights in the two networks (in the form of 243 two NxN matrices containing the edge weights) were correlated (Farine 2018). We compared

244 the result with the same test applied to the permuted networks (described above). To illustrate 245 the network structure over the two periods, we also created a graph of each network (Fig. 3;

246 left 1997 and right 2016). For the purpose of plotting the networks, we used the same

247 permutation procedure (described above) to identify edges (co-occurrence between two 248 species) that were significantly stronger than expected by chance. That is, for each edge we 249 determined whether the observed edge weight was greater than $95 \%$ of the weights in the 250 randomized networks (following Whitehead 1999), and removed non-significant edges. All 251 analyses were conducted on the complete network.

253 Are traded species more central in the networks than non-traded species?

254 We tested whether traded species were more central in their network (for each year 255 separately). Centrality was measured using the weighted degree, which refers to the structural 256 importance based on position in the network (Farine \& Whitehead 2015). A greater propensity 257 to participate in mixed flocks, or occur in more species-diverse flocks, results in a higher 258 weighted degree. We fitted a linear model to evaluate the relationship between the species 
centrality values and their trade scores. Because networks data are inherently non-

260 independent, the $\mathrm{P}$ value was again derived using our permutation test (described above), this

261 time comparing the observed slope of the linear model to the $95 \%$ range of the slopes

262 calculated using the randomised networks (Farine \& Whitehead 2015). As an alternative test,

263 we compared the means for all traded species versus all non-traded species, calculating the $\mathrm{P}$

264 value by comparing the observed difference in means to the differences in means after 1000

265 permutations of the data.

266

267 Has the centrality of traded and non-traded species changed over time?

268 To test whether traded and non-traded species changed in their centrality over the 19 years,

269 we subtracted the weighted degree of each species in the 1997 network from their weighted

270 degree in the 2016 network. We then fitted a linear model with change in degree as a function

271 of trade score, using the same permutation approach described above to calculate significance

272 (Farine \& Whitehead 2015). We also conducted a simpler analysis in which we compared the

273 proportion of species that increased versus decreased their centrality (as a binary measure)

274 against trade score (as a binary measure), calculating the P value by comparing the difference in

275 the proportion of species that decreased in their centrality in the observed data versus the

276 randomised networks.

277

278 Are mixed-species flocks resilient to the loss of central species?

279 We conducted a simulated removal experiment to determine how losing central traded species 280 from the system would impact community structure. In many networks, the majority of the 
281 structure is determined by a few central nodes, and losing these nodes could reduce the

282 viability of the network. In this simulation, we sequentially removed species with the highest

283 overall centrality values (i.e. summing the centrality values from the 1997 and the 2016

284 networks) and a trade score of 1 or more, starting with the species that was the most central.

285 Removing a species involved removing it from both of the observed networks as well as all of

286 the corresponding randomised networks. We then calculated the correlation between the 1997

287 and 2016 networks, having removed those species, using the same Mantel test procedure

288 described above (including comparing the results of the Mantel test applied to the observed

289 network with those using the randomised networks). We avoided calculating properties of the

290 networks resulting from the node removals, as the biological relevance of metrics such as

291 average centrality are unclear. Instead we focused on using this test to ask about how many

292 species have contributed towards maintaining consistent structure (i.e. correlations) in the

293 network across the 20 year period, and ultimately determine whether the mixed flock networks

294 are robust to the loss of central species. By restricting our analysis to removing the same

295 species from the paired networks and measuring the correlation between these, we also aim to

296 minimize the limitations drawn by the fact that networks are likely to re-wire in response to

297 changes in species' presence or abundance (assuming they would rewire in approximately the 298 same way).

299

300 Results

301 In total, we observed 184 flocks in 1997 and 135 flocks in 2016. Flocks were comprised of 90

302 species in total (78 species in 1997 and 59 species in 2016; Table A1). Of the 90 species that 
303

304

305

306

307

308

309

310

311

312

313

314

315

316

317

318

319

320

321

322

323

324

were recorded participating in mixed flocks, one species has a Vulnerable status (Ruby-throated Bulbul Pycnonotus dispar) and 23 species are listed as Near-Threatened. The dominant foraging guild was insectivore (60 species). A further 25 species fed on insects but also include fruits and or nectar in their diet. Three species were frugivores, one was a predator of small vertebrates, and one was a terrestrial omnivore.

A total of 47 species were observed participating in mixed flocks in both sampling periods, with 31 species only recorded in 1997 and 12 species only recorded in 2016 . The number of species detected in a single mixed flock ranged from 2 to 15 species in 1997 with a mean of $5.15 \pm 2.8$ SD, and 2 to 22 species in 2016 with a mean of $4.46 \pm 2.77$ SD. The total number of edges (species co-occurrence in mixed flocks) was 962 in the 1997 network and 572 in 2016 . Using information from the published literature on bird trade, we identified 49 species that were part, or very likely to be part, of the bird trade in Sumatra. Of these, 44 were previously identified by Harris et al. (2017) from the same study site (see Table A2), and our study added an additional 5 species that were not observed in that study.

Are communities more structured than expected under indiscriminate flocking?

We constructed a separate social network for each of the two sampling periods (1997 and 2016). Summary statistics for these networks can be found in Table A3. We then tested whether the structure of these networks differed from networks formed by species flocking indiscriminately with others (but maintaining the same flock sizes). In the 1997 network, the comparison of the coefficient of variation (CVobserved) with the coefficient of variation from 
325 the randomization process (CVrandom) was significantly higher than random (CVobserved=253,

$326 P_{\text {rand }}=0.003$; Fig. 4). By contrast, the 2016 network did not differ from chance (CVobserved=376,

$327 \quad P_{\text {rand }}=0.145$; Fig. 4), meaning that we cannot say that the species differentiate in their mixed

328 flock attendance more than expected by chance (i.e. species participated in mixed flocks

329 randomly with respect to species composition).

331 Are the 1997 and 2016 networks correlated?

332 Assuming that no anthropogenic disturbances occurred in the study site, we predicted that the 3331997 and 2016 networks should be correlated. Despite the fact that the 2016 network did not 334 differ from indiscriminate flocking (see above), the correlation in the edge weights between the 335 two networks was greater than expected by chance (Mantel $r=0.14, P_{\text {rand }}=0.007$ ). This reflects 336 some general stability in terms of flock membership. However, the correlation was relatively 337 low and we observed some major shifts. From five species with the highest weighted degree 338 values in 1997, only two species were in the top five species in 2016: the Blue-winged Leafbird 339 and the Bronzed Drongo Dicrurus aeneus (Appendix S1). In 2016, the Asian Fairy-bluebird was 340 the most central (weighted degree=5.49), despite being peripheral in the 1997 network 341 (weighted degree=0.82).

343 Are traded species more central in the networks than non-traded species?

344 From the total of 90 species observed in mixed flocks (combined from the two samples), slightly 345 more than half (54.4\%) were identified as traded species (i.e. trade score $>0$ ). In both networks, 346 we found that the traded species had significantly higher centrality values (weighted degree) 
347 than the non-traded species $\left(\beta \pm S E=0.126 \pm 0.153, P_{\text {rand }}=0.019\right.$ for the 1997 network, and $\beta \pm$ $348 \mathrm{SE}=0.356 \pm 0.173, \mathrm{P}_{\text {rand }}=0.002$ for the 2016 network; Fig. 5). For example, the most central 349 species in both years (1997: Blue-winged Leafbird, weighted degree=5.40; 2016: Asian Fairy

350 Bluebird Irena puella, weighted degree=5.49) were traded species. The most central non-traded 351 species were Raffless Malkoha Rhinortha chlorophaeus (1997, weighted degree=4.76) and 352 Black-winged Flycatcher-shrike Hemipus hirundinaceus (2016, weighted degree=4.20). These 353 results were confirmed when using a binary score for trade status: in 1997 the mean degree for 354 traded species was 1.88 versus 1.58 for untraded species $\left(P_{\text {rand }}=0.008\right)$, while in 2016 the mean 355 for traded species was 1.83 versus 1.17 for untraded species ( $\left.P_{\text {rand }}=0.004\right)$. This latter analysis 356 also reveals that the steeper relationship between trade score and centrality in $2016(\beta=0.356)$ 357 versus 1997 ( $\beta=0.126)$ is driven by a lower centrality in non-traded species in the latter year, 358 rather than an absolute increase in centrality in traded species (see also Fig. 5).

Has the centrality of traded and non-traded species changed over time?

361 By substracting the weighted degree for each species in 2016 from their weighted degree in 362 1997, we calculated the change in centrality over time. We found that species with higher trade 363 scores had a significantly larger reduction in their weighted degree than non-traded species, 364 and this reduction was larger than expected when compared to the randomised networks $(\beta \pm$ $365 S E=-0.231 \pm 0.196, P_{\text {rand }}=0.035 ;$ Fig. 6). Although this effect is relatively small, it does suggest 366 that the species with the highest trade score have an approximately $36 \%$ reduction in degree 367 relative to the non-traded species. From 49 traded species, we found a reduction in centrality in 36820 species (41\%), whereas only 12 species out of 41 non-trade species ( $29 \%$ ) decreased in 
centrality, which was a larger difference than expected when compared to the randomised networks $\left(P_{\text {rand }}=0.020\right)$.

\section{Are mixed-species flocks resilient to the loss of central species?}

We simulated the sequential removal of 10 traded species (from all networks) with the highest combined centrality values to test how resilient this correlation was to the further loss of central species. The simulation revealed a decrease in correlation between the network in 1997 and 2016 (black points in Fig. 7). After removal of the most central traded species (Blue-winged Leafbird), the network correlation was still different from random (i.e. the network still contained more consistent preferred/avoided relationships across the two samples than expected by chance). However, the correlation across the two networks became inseparable from random after removal of the second species onwards. This suggests that the further loss of just two traded species, on top of the existing changes already experienced in the system, could be sufficient to completely break down the structure of mixed-species flocking that was observed in the system prior to the onset of the bird trade in the study area.

\section{Discussion}

Mixed flocks represent an important social system in bird communities (Buskirk 1976; Munn 1985). To date, two main anthropogenic disturbances- forest fragmentation and land-use intensity - have been identified as causing negative effects on mixed flocking community structure (e.g., on species richness; Goodale et al. 2015). In this study, we demonstrate an additional potential effect-trapping for the bird trade-on structure in an avian community. 
391 Using data collected from the same forest subject to bird trapping almost 20 years apart, we

392 found that mixed-species flocks observed in 2016 did not show evidence for containing

393 preferred associations between species, unlike flocks observed in 1997. Flock sizes typically

394 contained fewer species (but the same number of individuals per species), meaning that the

395 resulting networks were less densely connected and with a lower mean degree, despite

396 maintaining similar characteristics such as local clustering (see Table A2). Together, our finding

397 suggest that the overall system has been disturbed. We then show evidence that changes in the

398 network centrality of species was linked with their status in the bird trade. Finally, using

399 simulations, we also showed that the current system may not be resilient to the complete loss

400 of two or more of the currently traded species. Our results suggest that trapping is likely to be

401 contributing to the degradation of mixed-species flocking patterns, affecting both traded and

402 non-traded species, and therefore could lead to widespread declines in the broader community

403 structure of species that rely on mixed flocks for survival.

404

405 More than half of the species that participated in mixed flocks were traded. In both 1997 and

406 2016, these traded species had significantly higher centrality values than non-traded species.

407 This finding suggests that, by being regular participants in flocks, traded species are likely to be

408 important contributors to the maintenance of mixed flocks in this community. The fact that

409 traded species were central in both periods is perhaps testament to having received some

410 protection at the study site. However, despite this protection trapping remained active and we

411 found that traded species had a significantly greater decrease in centrality over the two time

412 periods than did non-traded species. While this could seemingly have arisen because the traded 
413 species have become less common, all of our analysis were based on permutation tests that

414 only swap the identities of species observed in mixed flock (rather than generating flocks at

415 random), thus maintaining constant the number of observations per species (i.e. the abundance

416 in mixed flocks) in our statistical testing. Thus, if a pattern differs from chance, it differs from

417 the distribution of the null hypothesis that is drawn using exactly the same number of

418 observations, and therefore represents a significant change independent of changes in how

419 often each species was observed. The hypothesis that changes occurred due to declines in

420 abundance therefore seems unlikely. Rather it appears that the bird trade has driven a change

421 in behaviour of several, or many, species.

422

423 The changes in species' flocking behaviour could be because being targeted by bird traders

424 changes their behaviour, or their perceived value by other species. For example, associating

425 with Blue-winged Leafbirds may now be less beneficial or more risky than it was 20 years ago.

426 While this process remains speculative, changes in behaviour in relation to risk has been noted

427 in a number of relevant studies. For example, Hua et al. (2013) conducted playbacks of

428 predators in habitat patches and found that while some species reduced in abundance

429 (suggesting they left those patches), others instead became more cryptic (i.e. they reduced in

430 their observability). A more directly relevant example is the White-rumped Shama, a species

431 that is valued for its song and easily trapped (including in Sumatra) because of its combative

432 response to playback (Eaton et al. 2015). During surveys conducted in Way Kambas National

433 Park, Lampung (Sumatra), birds were noted as being silent when discovered, and only sang very

434 quietly in response to playback (Eaton et al. 2015). This change in behaviour may have evolved 
because combative individuals are more easily caught, and thus trapping has generated strong selection against responding to vocalisations. Vocalisations have been widely reported as being important for the formation and maintenance of mixed flocks (Goodale \& Kotagama, 2006; Pagani-Núñez et al., 2018). Selecting for reduced vocalizing could change the attractiveness of the species. Thus, the pursuit of highly prized species in the bird trade could affect communities not just directly as a result of removal of birds and mortality during bycatch, but also if the effect of being caught drives behavioural changes in species (both targeted and non-targeted) within the community.

We also conducted simulations to investigate the effect of complete removal of traded species, and found that the overall community is potentially not very resilient to the loss of important species (i.e. those species that interact with many species and were observed to be central). Although this is the worst case scenario (i.e. extinction of species from the forest) and a relatively simplistic simulation (i.e. it does not account for re-structuring of the network in case of a loss of a species), it at least indicates the urgency to protect traded species that are important contributors to mixed flocks. In an effort to initiate conservation efforts, the first Songbird crisis summit was held in 2015 in response to the songbird trade in the Greater Sunda region, and tried to identify the most threatened songbirds and propose actions to save them from extinction (Lee et al. 2016). The second meeting was held at the beginning of 2017. They identified 28 priority species, in which three species have been identified as forming mixed flocks: White-rumped Shama, Grey-cheeked Bulbul, and Asian Fairy Bluebird. The latter is particularly important as we found that it had replaced other species as the most central in the 
4572016 mixed flock network. Thus, the protection of species will need to be dynamic if the

458 behaviour of the traders and of the species are both responding to the changing dynamics in

459 these songbird communities.

461 The capture of species in flocks arising from the wildlife trade could have additional broader

462 impacts. From the 90 species recorded participating in mixed flocks, 21 species include fruits as

463 part of their diet where 17 species were categorized as traded species (had been recorded in

464 the bird market). Considering their potential roles in seed dispersal and the potential impact of

465 bird trade to their population, the bird trade might also affect seed dispersal within these

466 systems. Several flock-attending species, such as Red-throated Barbet Psilopogon

467 mystacophanos, Spectacled Bulbul Pycnonotus erythropthalmos, and Yellow-bellied Bulbul

468 Alophoixus phaeocepahlus, incorporate a large amount of fruit in their diet. Declines in these

469 species could potentially limit their effectiveness at dispersing some fruits, as has been shown

470 in other studies (e.g. McConkey \& O'Farril 2016). However, whether any fruiting species rely

471 heavily on species that form mixed flocks for seed dispersal in our study area is unknown, and

472 warrants further investigation.

474 Social network analysis is a powerful tool for wildlife conservation (Snijders et al. 2017).

475 Although the impact of anthropogenic disturbances (fragmentation or different land-use

476 intensity) on mixed-species flocking has been widely documented (e.g., Stouffer \& Bierregaard

477 1995, Maldonado-Coelho \& Marini 2000, Sridhar \& Sankar 2008, Goodale et al. 2015), only one

478 previous study used network analysis; examining the impact of forest fragmentation on mixed 
479 flock characteristics (Mokross et al. 2014). In that study, the associations among species, as

480 shown by weighted degree, declined with increasing level of forest fragmentation and

481 secondary forest (Mokross et al. 2014). This means that there was a reduction in mixed flock

482 attendance with increasing habitat disturbance (Mokross et al. 2014). This result was also not

483 attributed to a reduction in species abundance: despite several species having lower

484 abundance, they still persisted in the degraded habitats (Stouffer et al. 1995; Mokross et al.

485 2014). Social network analysis allowed us to find almost identical evidence of changes in mixed

486 flock composition, with reduced richness and reduced weighted degree in 2016 compared to

487 1997. However, unlike in the previous study that focused on habitat effects, our changes arose

488 from trapping from the bird trade.

489

490 It is becoming increasingly clear that mixed-species flocking plays an important part in the

491 social system of many bird species. By using network analysis we evaluated the potential

492 impact of bird trapping to mixed flocks in Sumatra. We note that the bird trade is notoriously

493 difficult and dangerous to study. We made use of the best available and most local data we

494 could find, and these data match the sentiment based on our, and others', experience of the

495 study area. Traded species are important component of mixed flocks in our study area. By

496 comparing data on mixed flocks from surveys almost 20 years apart, we have shown a

497 degradation of the structure of mixed species flocks over time (measured independently of the

498 trade score), and significant reductions in the centrality of traded species in mixed flock

499 networks (both in terms of their score and a simple traded versus non-traded status, and using

500 a permutation test that controlled for potential changes in abundance over the two sampling 
501 periods). Although the mechanisms leading to reduced attendance of species in mixed flocks

502 are still not clear, our data suggests that bird trapping could have impacts beyond reductions in

503 abundance alone. It is well established that the absence of nuclear species can significantly

504 impact the behaviour of remaining species (Dolby \& Grub 1998; Dolby \& Grub 2000). We add

505 the suggestion that the perceived value of traded species to other attendant species in their

506 flocks might also be reduced as a result of changes in behaviour or due to the higher risk of

507 being caught as bycatch, even if they are not completely absent. Thus, both direct and indirect

508 effects of the bird trade on other flock participants may occur, and require urgent investigation.

509 Further, protection and enforcement will need to be strengthened to protect not only species

510 that have been identified as being in decline, but also to protect species that play an important

511 role in the broader avian community (i.e. those that are central in mixed flocks, contributing

512 either functionally or as attendant species contributing towards group augmentation).

\section{Supporting Information}

515 Additional supporting tables including: Table A1: a table of bird species observed in mixed

516 flocks with their trade scores and respective weighted degree values in 1997 and 2016

517 (Appendix S1), Table A2: table of species identified as traded by Harris et al. 2017, a study

518 conducted at the same study site as us, and Table A3: a table containing summary statistics of

519 the survey data and the resulting networks. The authors are solely responsible for the content

520 and functionality of these materials. Queries should be directed to the corresponding author. 


\section{Data accessibility}

523 Raw data and R scripts can be downloaded from: https://dx.doi.org/10.17617/3.1a

524

525 Literature cited

526 Adeney JM, Ginsberg JR, Russell GJ, Kinnaird MF (2006). Effects of an ENSO-related fire on birds 527 of a lowland tropical forest in Sumatra. Animal conservation 9: 292-301.

528 Aplin LM, Farine DR, Morand-Ferron J, Sheldon BC. 2012. Social networks predict patch discovery in a wild population of songbirds. Proceedings of the Royal Society of London B 279: 4199-4205.

Arbeláez-Cortés E, Rodríguez-Correa HA, Restrepo-Chica M. 2011. Mixed bird flocks: patterns of activity and species composition in a region of the Central Andes of Colombia. Revista Mexicana de Biodiversidad 82: 639-651.

534 Bejder L, Fletcher D, Brager S. 1998. A method for testing association patterns of social animals. Animal Behaviour 56: 719-725. flocks. Emu 82:256-275. Species, Co-Occurrence, and Function. Science, 339(6127), 1611-1615. 
540 Buskirk WH. 1976. Social systems in a tropical forest avifauna. The American Naturalist 110:

541 293-310.

542

543

544

545

546

547

548

549

550

551

552

553

554

555

556

Chng SCL, Eaton JA, Krishnasamy K, Shepherd CR, Nijman V. 2015. In the market for extinction: An inventory of Jakarta's bird markets. TRAFFIC, Petaling Jaya, Selangor, Malaysia.

Chng SCL, Eaton JA. 2016. In the Market for Extinction: Eastern and Central Java. TRAFFIC. Petaling Jaya, Selangor, Malaysia.

Develey PF, Peres CA. 2000. Resource seasonality and the structure of mixed species bird flocks in a coastal Atlantic forest of south-eastern Brazil. Journal of Tropical Ecology 16: 33-53.

Dolby AS, Grubb TC. 1998. Benefits to satellite members in mixed-species foraging groups: an experimental analysis. Animal Behavior 56: 501-509.

Dunne JA, Williams RJ, Martinez, ND. 2002. Network structure and biodiversity loss in food webs: robustness increases with connectance. Ecology Letters, 5(4), 558-567.

Eaton JA, Shepherd CR, Rheindt FE, Harris JBC, van Balen S, Wilcove DS, Collar NJ. 2015. Tradedriven extinctions and near-extinctions of avian taxa in Sundaic Indonesia. Forktail 31: 112.

Eguchi K, Yamagishi S, \& Randrianasolo V. 1993. The Composition and Foraging Behavior of Mixed-Species Flocks of Forest-Living Birds in Madagascar. Ibis 135: 91-96. 
557 Farine DR, Aplin LM, Garroway CJ, Mann RP, Sheldon BC. 2014. Collective decision making and

558

559

560

561

562

563

564

565

566

567

568

569

570

571

572

573

574

575

social interaction rules in mixed-species flocks of songbirds. Animal Behaviour 95: 173182.

Farine DR, Aplin LM, Sheldon BC, Hoppitt W. 2015. Interspecific social networks promote information transmission in wild songbirds. Proceedings of the Royal Society of London B 282: 20142804.

Farine DR. 2013. Animal social network inference and permutations for ecologists in R using asnipe. Methods in Ecology and Evolution 4: 1187-1194.

Farine DR. 2017. A guide to null models for animal social network analysis. Methods in Ecology and Evolution 8: 1309-1320.

Farine DR. 2018. When to choose dynamic vs. static social network analysis. Journal of Animal Ecology 87: 128-138.

Farine DR, Whitehead H. 2015. Constructing, conducting and interpreting animal social network analysis. Journal of Animal Ecology 84: 1144-1163.

Franks DW, Ruxton GD, James R. 2010. Sampling animal association networks with the gambit of the group. Behavioral Ecology and Sociobiology 64: 493-503.

Gaveau DL, Wandono H, Setiabudi F. 2007. Three decades of deforestation in southwest Sumatra: Have protected areas halted forest loss and logging, and promoted re-growth? Biological Conservation 134: 495-504. 
576 Goodale E, Beauchamp G, Ruxton GD 2017. Mixed-species groups of animals: Behavior, Community Structure, and Conservation. London, United Kingdom: Academic Press.

578 Goodale E, Ding P, Liu X, Martínez A, Si X, Walters M, Robinson SK. 2015. The structure of 579 mixed-species bird flocks, and their response to anthropogenic disturbance, with special $580 \quad$ reference to East Asia. Avian Research 6: 1.

581 Goodale E, Kotagama SW. 2005. Alarm calling in Sri Lankan mixed-species bird flocks. Auk 122:

582 108-120.

Goodale E, Kotagama SW. 2006. Vocal mimicry by a passerine bird attracts other species involved in mixed-species flocks. Animal Behaviour, 72, 471-477.

585 586

Gotelli NJ, Graves GR. 1996. Null models in ecology. Washington, DC, USA: Smithsonian Institution Press.

Harris JBC, Tingley MW, Hua F, Yong DL, Adeney JM, Lee TM, Marthy W, Prawiradilaga DM, Sekercioglu $\mathrm{CH}$, Suyadi, Winarni N, Wilcove DS. 2017. Measuring the impact of the pet trade on Indonesian birds. Conservation Biology 31: 394-405.

Herzog SK, Soria R, Troncoso A, Matthysen E. 2002. Composition and structure of avian mixedspecies flocks in a high-Andean Polylepis forest in Bolivia. Ecotropica 8: 133-143.

Hua FY, Fletcher RJ, Sieving KE, Dorazio RM. 2013. Too risky to settle: avian community structure changes in response to perceived predation risk on adults and offspring. Proceedings of the Royal Society B-Biological Sciences, 280: 20130762. 
595 Hutto RL. 1987. A description of mixed-species insectivorous bird flocks in western Mexico.

$596 \quad$ Condor 89: 282-292.

597 Hutto RL. 1994. The composition and social organization of mixed-species flocks in a tropical 598 deciduous forest in Western Mexico. Condor 96: 105-118.

599 Jepson P, Ladle RJ. 2009. Governing bird-keeping in Java and Bali: evidence from a household 600 survey. Oryx 43: 364-374.

601 Jullien M, Clobert J. 2000. The survival value of flocking in Neotropical birds: reality or 602 fiction? Ecology 81: 3416-3430.

603 Kotagama SW, Goodale E. 2004. The composition and spatial organization of mixed-species 604 flocks in a Sri Lankan rainforest. Forktail 20: 63-70.

605 Kinnaird MF, O'Brien TG. 1998. Ecological effects of wildfire on lowland rainforest in Sumatra. 606 Conservation Biology 12: 954-956.

607 Latta SC, Wunderle JM. 1996. The composition and foraging ecology of mixed-species flocks in 608 pine forests of Hispaniola. Condor 98: 595-607.

609 Lee TM, Soh MCK, Sodhi N, Koh LP, Lim SLH. 2005. Effects of habitat disturbance on mixed 610 species bird flocks in a tropical sub-montane rainforest. Biological Conservation 122: 193611204. 
Lee JGH, Chng SCL, Eaton JA (eds). 2016. Conservation strategy for Southeast Asian songbirds in trade. Recommendations from the first Asian Songbird Trade Crisis Summit 2015 held in Jurong Bird Park, Singapore, 27-29 September 2015.

Maldonado-Coelho M., Marini MA. 2000. Effects of forest fragment size and successional stage on mixed-species bird flocks in south-eastern Brazil. Condor 102: 585-594.

Mammides C, Chen J, Goodale UM, Kotagama SW, Sidhu S, Goodale E. 2015. Does mixedspecies flocking influence how birds respond to a gradient of land-use intensity? Proceedings of the Royal Society B-Biological Sciences 282: 20151118.

Martinez AE, Gomez JP, Ponciano JM, Robinson SK. 2016. Functional Traits, Flocking Propensity, and Perceived Predation Risk in an Amazonian Understory Bird Community. The American Naturalist 187: 607-619.

Martinez AE, Zenil RT. 2012. Foraging guild influences dependence on heterospecific alarm calls in Amazonian bird flocks. Behavioral Ecology 23: 544-550.

McConkey KR, O'Farrill G. 2016. Loss of seed dispersal before the loss of seed dispersers. Biological Conservation 201: 38-49.

Mokross K, Ryder TB, Côrtes MC, Wolfe JD, Stouffer PC. 2014. Decay of interspecific avian flock networks along a disturbance gradient in Amazonia. Proceedings of the Royal Society of London B 281: 20132599.

Moynihan M. 1962. The organization and probable evolution of some mixed species flocks of Neotropical birds. The Smithsonian Miscellaneous Collection 143: 1-140. 
632 Miller ET, Farine DR, Trisos $\mathrm{CH}$. 2017. Phylogenetic community structure metrics and null models: a review with new methods and software. Ecography 40: 461-477.

634 Munn CA. 1985. Permanent canopy and understorey flocks in Amazonia: species composition 635 and population density. Ornithological Monographs 36:683-712.

636 O'Brien TG, Kinnaird MF. 1996. Birds and mammals of the Bukit Barisan Selatan National Park, Sumatra, Indonesia. Oryx 30: 207-217.

Pagani-Núñez E, Xia X, Beauchamp G, He R, Husson JHD, Liang D, Goodale E. in press. Are vocal characteristics related to leadership patterns in mixed-species bird flocks? Journal of Avian Biology. doi:10.1111/jav.01674

R Core Team. 2014. R: A language and environment for statistical computing. R Foundation for 642 Statistical Computing, Vienna, Austria. URL http://www.R-project.org/.

643 Satischandra SHK, Kudavidanage EP, Kotagama SW, Goodale E. 2007. The benefits of joining 644 mixed-species flocks for a sentinel nuclear species, the Greater Racket-tailed Drongo Dicrurus paradiseus. Forktail 23: 145-148.

Shepherd CR, Sukumaran J, Wich SA. 2004. Open season: an analysis of the pet trade in Medan, Sumatra 1997-2001. TRAFFIC Southeast Asia, Petaling Jaya, Selangor, Malaysia.

649 Shepherd CR. 2012. The owl trade in Jakarta, Indonesia: a spot check on the largest bird 650 markets. Birding Asia 18:58-59. 
651 Snijders, L., Blumstein, D.T., Stanley, C.R., Franks, D.W. 2017. Animal Social Network Theory Can Help Wildlife Conservation. Trends in Ecology \& Evolution 32:567-577.

653 654 655 656 657 658 659 660 661 662 663 664 665 666 667 668 669

Sridhar H, Sankar K. 2008. Effects of habitat degradation on mixed-species bird flocks in Indian rain forests. Journal of Tropical Ecology 24:135-47.

Sridhar H, Beauchamp G, Shanker K. 2009. Why do birds participate in mixed-species foraging flocks? A large-scale synthesis. Animal Behaviour 78: 337-347.

Sridhar H, Jordán F, Shanker K. 2013. Species importance in a heterospecific foraging association network. Oikos 122: 1325-1334.

Sridhar H, Shanker K. 2014. Using intra-flock association patterns to understand why birds participate in mixed-species foraging flocks in terrestrial habitats. Behavioral ecology and sociobiology 68: 185-196.

Stouffer PC, Bierregaard Jr RO. 1995. Use of Amazonian forest fragments by understory insectivorous birds. Ecology 76: 2429-2445.

Suzuki TN. 2012. Long-Distance calling by the Willow Tit, Poecile montanus, facilitates formation of mixed-species foraging flocks. Ethology 118.1: 10-16.

Thiollay JM. 1999. Frequency of mixed species flocking in tropical forest birds and correlates of predation risk: an intertropical comparison. Journal of Avian Biology 30:282-294.

UNODC. 2013. Transnational Organized Crime in East Asia and the Pacific. A threat assessment. United Nations Office on Drugs and Crime. 
670 van Marle JG, Voous KH. 1988. The birds of Sumatra: an annotated check-list (No. 10). British 671 Ornithologists' Union.

672 Whitehead H. 1999. Testing association patterns of social animals. Animal Behaviour 57: F26$673 \quad$ F29.

674 Whitehead H, Dufault S. 1999. Techniques for analyzing vertebrate social structure using 675 identified individuals: review. Advances in the Study of Behavior 28: 33-74.

676

677

678 


\section{Figure Legends}

680 Figure 1. Confiscated Blue-winged Leafbird Chloropsis moluccensis that was used as bait to 681 attract birds by the illegal bird trappers and examples of birds that died or were killed during the capturing process Photos were taken at the study site. Copyright: WCSIP/Fahrudin Surahmat.

Figure 2. Location of this study site in the Way Canguk Research Station within the Bukit Barisan Selatan National Park, Lampung-Sumatra, Indonesia.

Figure 3. Networks of significant relationships in each of the two periods, 1997 (left) and 2016 (right). In each network, nodes represent species and the edges represent the probability of observing both species in a flock given that one was observed. The size of the node represents the weighted degree for each species in the network comprising only non-random comemberships in mixed flocks. The colour of the nodes represents the species' trade scores (brightest red $=2.5$, lightest blue $=0$, and grey $=1.5$ ).

693

Figure 4. Comparison of the observed network structure to the structure expected under 695 indiscriminate flock membership. Points shows the coefficient of variation values (black dots) 696 from the 1997 and 2016 networks. Bars show the expected values (95\% range of the Coefficient 697 of Variation) based on a permutation test in which each species occurs the same number of 698 times but are randomly allocated to flocks. While the 1997 network differs from random (the 699 point is above the upper 95\% quantile), the 2016 network does not.

Figure 5. In both years, there was a significant relationship between trade score and centrality in 702 the network. Plots show the relationship between the observed trade score and the centrality 703 value (weighted degree) for each species in mixed flock networks in 1997 (left) and 2016 (right).

704 We calculated $P$ values by comparing the observed coefficient value (red line) with a distribution 705 of 1500 coefficient values drawn from a permutation test (see text). 
707 Figure 6. Species with a high trade score had a significantly greater decrease in network

708 centrality between 1997 and 2016. Plot shows the relationship between the observed change in

709 centrality value for each species in mixed flocks and their trade score. We calculated the $P$ value

710 by comparing the observed coefficient value (red line) with a distribution of 1500 coefficients

711 drawn from a permutation test (see text).

712

713 Figure 7. The structure of the 2016 mixed-species flocking network is not resilient to the loss of

714 more than one central traded species. Plot shows the correlation between the 1997 and 2016

715 networks (black dots) in the original network $(x=0)$, and after the simulated removal of up to 10

716 species with the highest degree that are part of the songbird trade. The bars represent the 95\%

717 range of the expected correlations based on the permutation test. Correlations where the black

718 points overlap with the bars are not significantly different from random.

719

720

721 
722 Figure 1

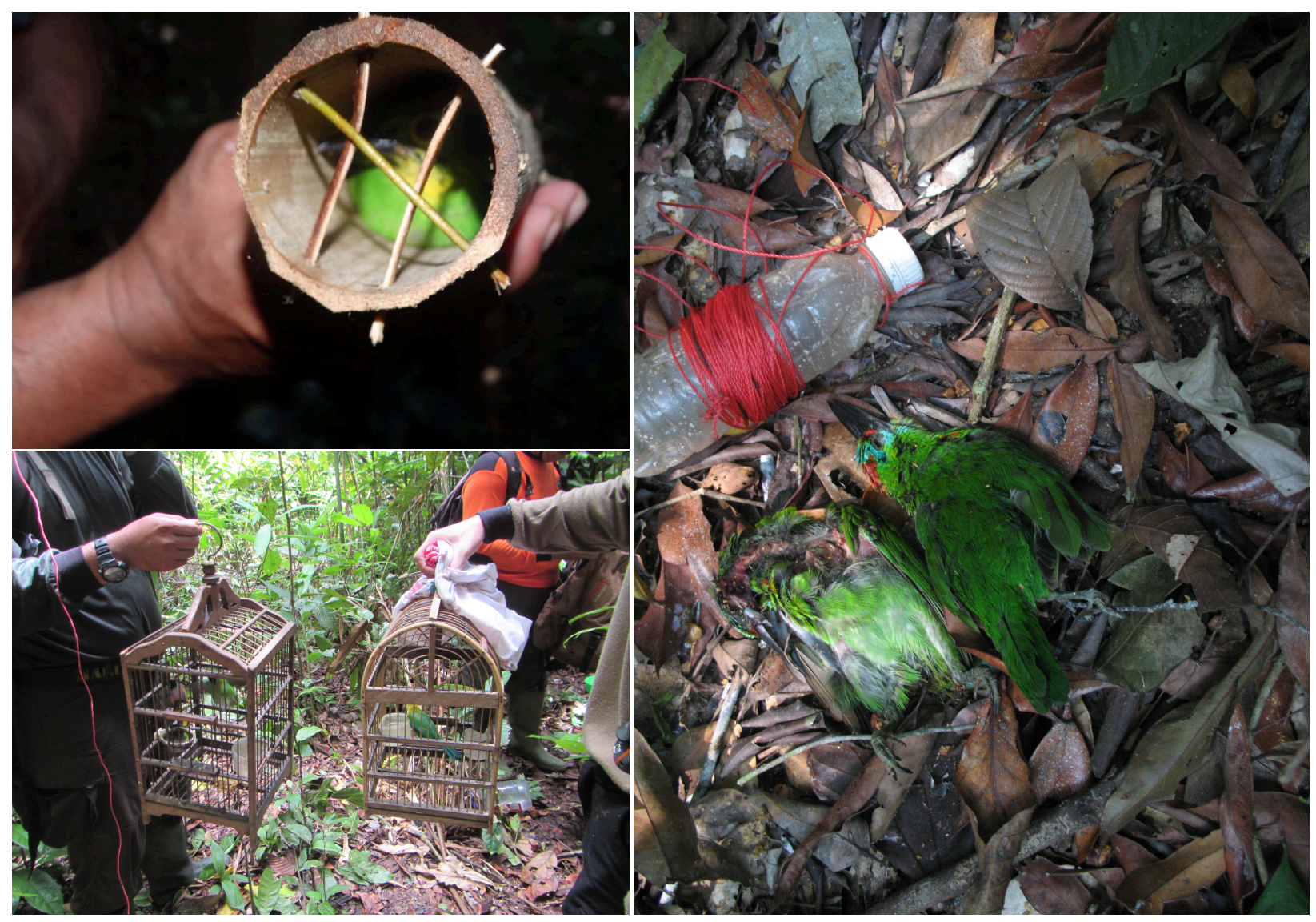

724

726

727

728

729

730

731

732

733 
Figure 2

735

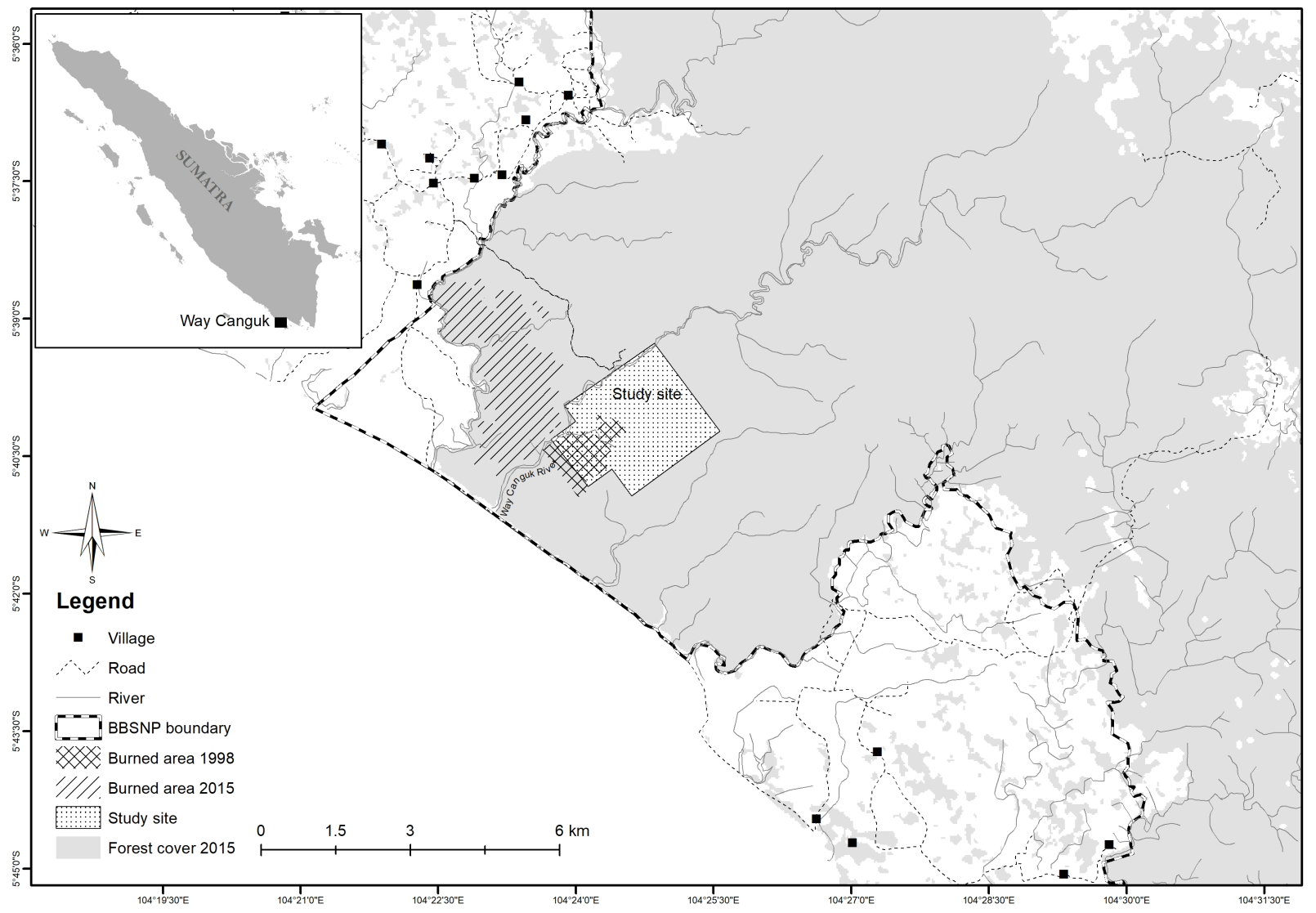




\section{$744 \quad$ Figure 3}

745

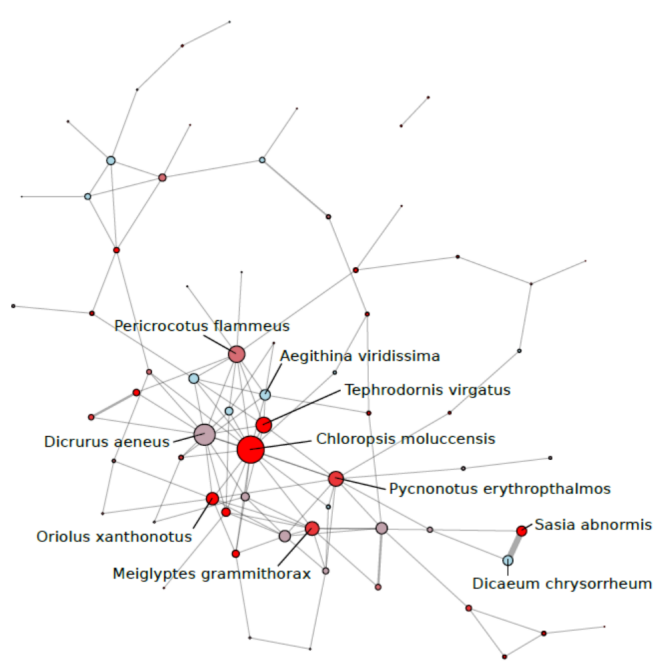

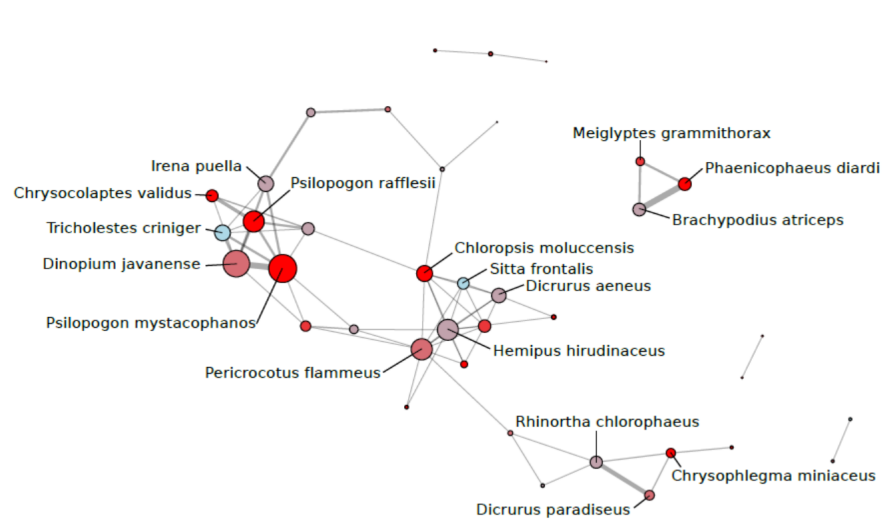


$746 \quad$ Figure 4

747

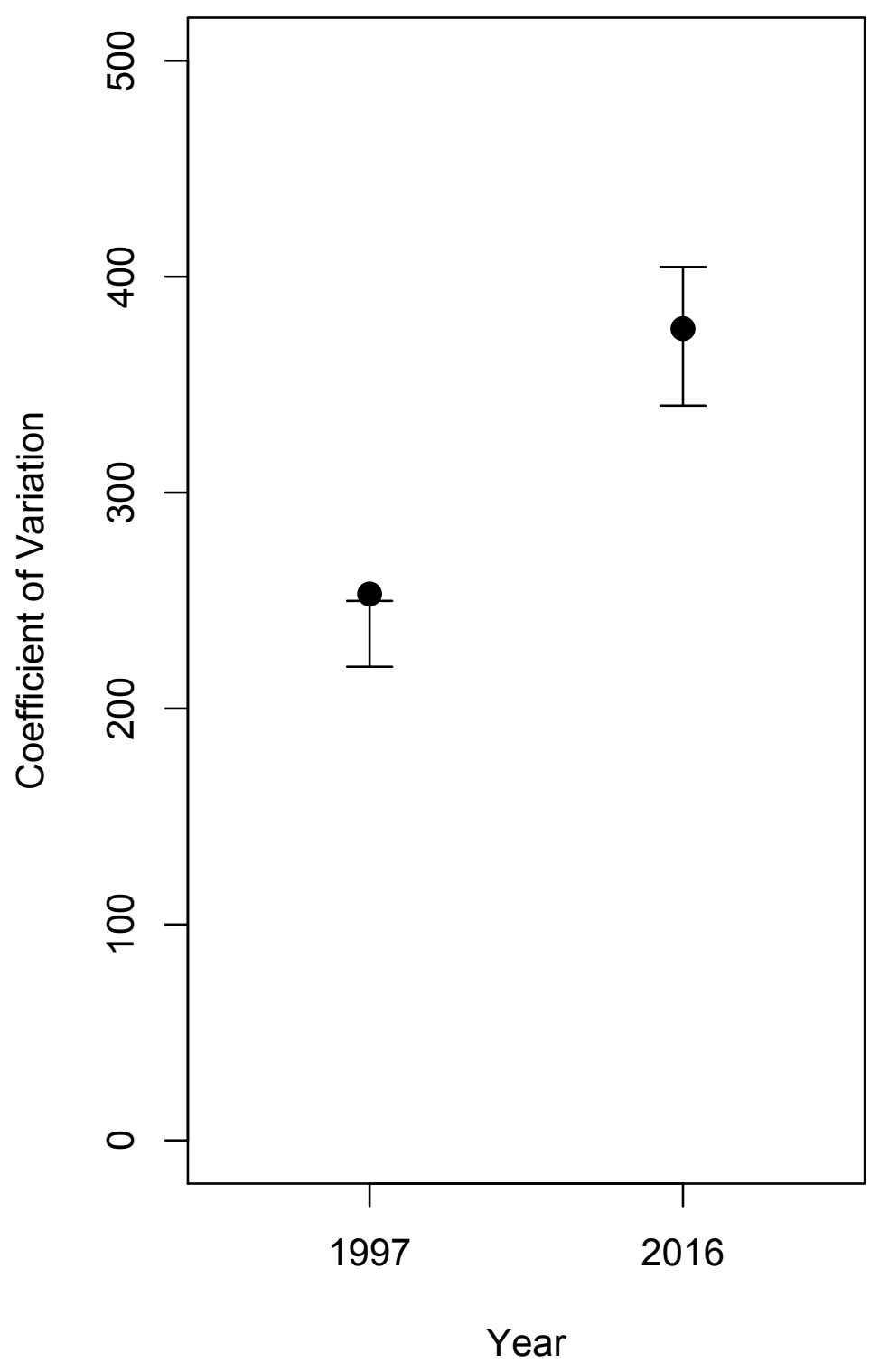

748

749

750 
751 Figure 5

752
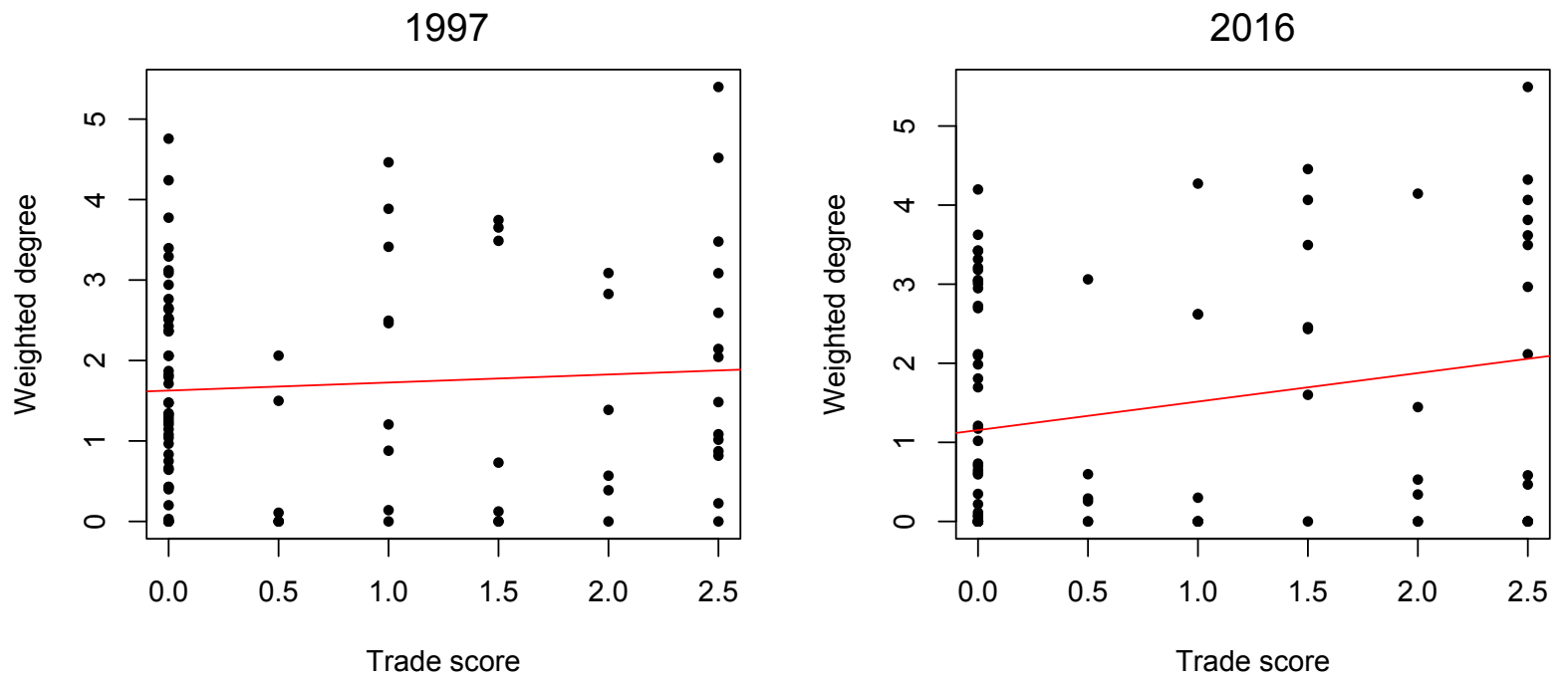

753

754

755

756

757

758

759 
760 Figure 6

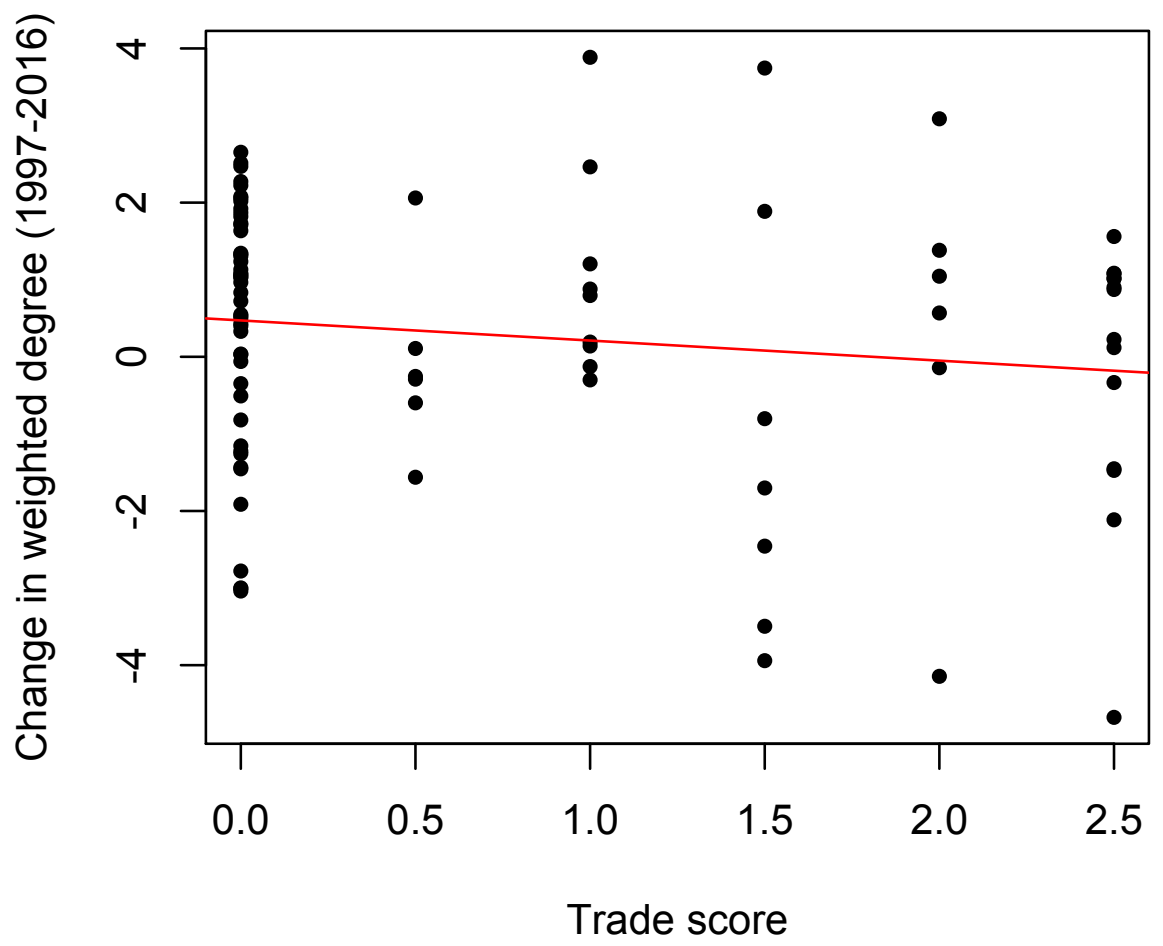

761

762

763 
$764 \quad$ Figure 7

765

766

767

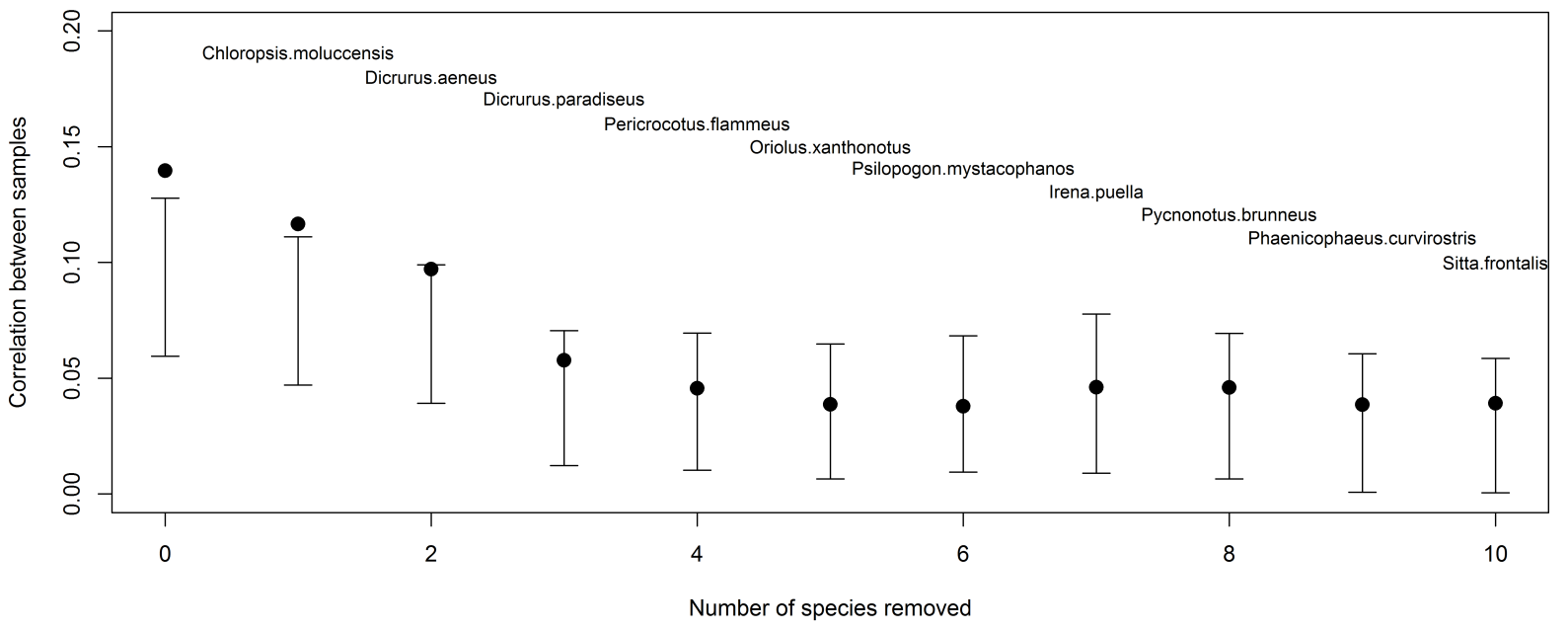

768

769

770

771

772

773

774 